\title{
CD2AP and Cbl-3/Cbl-c Constitute a Critical Checkpoint in the Regulation of Ret Signal Transduction
}

\author{
Cynthia C. Tsui ${ }^{1,3}$ and Brian A. Pierchala ${ }^{2,3}$ \\ ${ }^{1}$ Department of Internal Medicine, University of Michigan Medical School, Ann Arbor, Michigan 48109-0680, ${ }^{2}$ Department of Biologic and Materials \\ Sciences, School of Dentistry, University of Michigan, Ann Arbor, Michigan 48109-1078, and ${ }^{3}$ Department of Biological Sciences, The State University of \\ New York at Buffalo, Buffalo, New York 14260
}

The glial cell line-derived neurotrophic factor (GDNF) family ligands (GFLs) are critical for nervous system development and maintenance. GFLs promote survival and growth via activation of the receptor tyrosine kinase (RTK) Ret. In sympathetic neurons, the duration of Ret signaling is governed by how rapidly Ret is degraded after its activation. In an effort to elucidate mechanisms that control the half-life of Ret, we have identified two novel Ret interactors, CD2-associated protein (CD2AP) and Cbl-3. CD2AP, an adaptor molecule involved in the internalization of ubiquitinated RTKs, is associated with Ret under basal, unstimulated conditions in neurons. After Ret activation by GDNF, CD2AP dissociates. Similarly, the E3-ligase Cbl-3 interacts with unphosphorylated Ret and dissociates from Ret after Ret activation. In contrast to their dissociation from autophosphorylated Ret, an interaction between CD2AP and Cbl-3 is induced by GDNF stimulation of sympathetic neurons, suggesting that CD2AP and Cbl-3 dissociate from Ret as a complex. In neurons, the overexpression of CD2AP enhances the degradation of Ret and inhibits GDNF-dependent survival, and gene silencing of CD2AP blocks Ret degradation and promotes GDNF-mediated survival. Surprisingly, Cbl-3 overexpression dramatically stabilizes activated Ret and enhances neuronal survival, even though Cbl-family E3 ligases normally function to trigger RTK downregulation. In combination with CD2AP, however, Cbl-3 promotes Ret degradation rapidly and almost completely blocks survival promotion by GDNF, suggesting that Cbl-3 acts as a switch that is triggered by CD2AP and oscillates between inhibition and promotion of Ret degradation. Consistent with the hypothesis, Cbl-3 silencing in neurons only inhibited Ret degradation and enhanced neuronal survival in combination with CD2AP silencing. CD2AP and Cbl-3, therefore, constitute a checkpoint that controls the extent of Ret downregulation and, thereby, the sensitivity of neurons to GFLs.

Key words: GDNF; Ret; sympathetic neuron; neurotrophic factor; degradation; E3-ligase

\section{Introduction}

The glial cell line-derived neurotrophic factor (GDNF) family ligands (GFLs) constitute a family of four homologous neurotrophic factors that are vital to the development and maintenance of the nervous system and kidneys (Henderson et al., 1994; Arenas et al., 1995; Buj-Bello et al., 1995; Li et al., 1995; Mount et al., 1995; Oppenheim et al., 1995; Trupp et al., 1995; Moore et al., 1996; Pichel et al., 1996; Sánchez et al., 1996; Enomoto et al., 2000). The GFLs consist of GDNF, NRTN (neurturin), PSPN (persephin), and ARTN (artemin), all of which signal via a common receptor tyrosine kinase, Ret (Lin et al., 1993; Durbec et al., 1996; Kotzbauer et al., 1996; Treanor et al., 1996; Baloh et al., 1998b; Milbrandt et al., 1998; Rosenblad et al., 2000). The GFLs do not bind directly to Ret to activate it. Glycerophos-

\section{Received June 15, 2008; accepted July 22, 2008.}

This work was supported by the National Institutes of Health Grant K01 NS045221 and the Research Foundation of the State University of New York at Buffalo. We thank Tadashi Yamamoto, Mireille Cormont, and Stanley Lipkowitz for providing expression plasmids. We also thank Lauren Carr for secreterial assistance.

Correspondence should be addressed to Brian A. Pierchala, Department of Biologic and Materials Sciences, School of Dentistry, University of Michigan, 1011 North University, Ann Arbor, MI 48109-1078. E-mail: pierchal@umich.edu.

DOI:10.1523/JNEUROSCI.2738-08.2008

Copyright $\odot 2008$ Society for Neuroscience $\quad 0270-6474 / 08 / 288789-12 \$ 15.00 / 0$ phatidylinositol-anchored coreceptors, termed the GFR $\alpha$ coreceptors, act as the high-affinity binding proteins of the GFLs. This GFL-GFR $\alpha$ complex then associates with Ret and activates it (Baloh et al., 1997, 1998a; Buj-Bello et al., 1997; Klein et al., 1997; Cacalano et al., 1998; Enokido et al., 1998; Lindahl et al., 2000).

Activation-dependent downregulation of receptor tyrosine kinases (RTKs) is critically important for the termination of growth factor signals. Receptor downregulation, which controls the length of time that downstream signaling cascades are active, can dictate how the target cell responds. After its activation, Ret is rapidly ubiquitinated and degraded (Scott et al., 2005; Pierchala et al., 2006). This degradation pathway is the predominant means of termination of GFL signaling cascades and limits the effectiveness of GFLs as survival signals (Scott et al., 2005; Pierchala et al., 2006). Unlike other RTKs, Ret is degraded mainly by the proteasome, but the molecules required for this process are unknown (Pierchala et al., 2006). Inhibition of the ubiquitination and degradation of Ret underlies the ability of the heterologous neurotrophic factor nerve growth factor (NGF) to augment Ret signaling (Tsui-Pierchala et al., 2002a; Pierchala et al., 2007). NGFmediated Ret upregulation contributes considerably to the growth and metabolism-enhancing function of NGF on adult neurons (Tsui-Pierchala et al., 2002a). In addition to cross-talk 
signaling between NGF and Ret, other mechanisms of cross talk have been uncovered among other neurotrophic factor receptor pathways and between G-protein-coupled receptors (Lee and Chao, 2001; Lee et al., 2002; Popsueva et al., 2003). This implies that the elucidation of molecules responsible for communication between receptor signaling pathways will have widespread significance. We have identified two molecules, Cbl-3 and CD2associated protein (CD2AP), that are critical regulators of Ret downregulation. Cbl-3 and CD2AP together function as a checkpoint that controls the half-life of activated Ret and, therefore, the potency of GFL action.

\section{Materials and Methods}

Sympathetic neuronal cultures. Primary sympathetic neurons from the superior cervical ganglion (SCG) were generated and maintained in the presence of NGF as described previously (Tsui-Pierchala et al., 2002a). These neurons were maintained in vitro for 17-19 d. Before their exposure to GDNF, NGF was removed from the dissociated neurons. The neurons were then washed once and were next maintained with or without NGF for $48 \mathrm{~h}$ before GDNF stimulation.

Cell lines and transfections. HEK293 cells were maintained in growth medium consisting of DMEM (Sigma) containing 10\% fetal bovine serum (Invitrogen), glutamine, penicillin, and streptomycin. For transient transfections, the HEK293 cells were plated at a density of $2000 \mathrm{cells} / \mathrm{cm}^{2}$ and transfected 2 d later. HEK293 cells were transfected using calcium phosphate precipitation, and an expression plasmid encoding green fluorescent protein (GFP) was included in all transfections. Adequate transfection efficiency $(50-80 \%)$ was confirmed by visualizing the expression of GFP using a fluorescence microscope (Axiovert 200M; Zeiss). An equal amount of total plasmid DNA was used for each transfection, and the amount of each cDNA was also equal between each condition. We accomplished this by increasing or decreasing the amount of plasmid encoding GFP, depending on the number of molecules that were transfected in the various conditions. Immortalized mouse podocytes were maintained in vitro as described previously (Tsui et al., 2006). Flag-Cbl-3, Flag-Cbl-3 C351A, Flag-Cbl-3 G276E, and Flag-Cbl-3 TKB were kindly provided by Tadashi Yamamoto (University of Tokyo, Japan) (Kim et al., 2004).

Cbl-3 and CD2AP protein purification. An expression plasmid encoding full-length CD2AP was a kind gift from Mireille Cormont (INSERM, Nice, France) (Cormont et al., 2003). The coding region of CD2AP was subcloned into the pENTR vector system (Invitrogen) and subsequently cloned into the pDEST15 vector, thereby placing a glutathione $S$-transferase (GST) purification tag on the C terminus. These proteins were produced in BL21 cells and purified using glutathione agarose according to the manufacturer's instructions (Thermo Fisher Scientific). Expression plasmids encoding the short and long isoforms of human Cbl-3 were kind gifts from Stanley Lipkowitz (National Cancer Institute, Bethesda, MD) (Keane et al., 1999). The coding regions of these molecules were subcloned into the pDEST17 vector using the pENTR system (Invitrogen), which inserts a 6-histidine (6xHis) purification tag on the $\mathrm{C}$ terminus. These proteins were produced in BL21 cells and purified by immobilized metal ion affinity chromatography (IMAC) using $\mathrm{Ni}^{2+}$ nitrilotriacetic acid resin (Sigma).

In vitro binding experiments. To test whether Ret, CD2AP, and Cbl-3 directly interacted with each other, purified proteins were used. The recombinant GST-CD2AP and 6xHis-Cbl-3 described above served as the source of purified CD2AP and Cbl-3. Unphosphorylated, kinasedead Ret51 and autophosphorylated Ret51 were produced by overexpressing these proteins in HEK293 cells. After $24 \mathrm{~h}$, the cells were lysed at $4^{\circ} \mathrm{C}$ with a moderately denaturing buffer [ $10 \mathrm{~mm}$ Tris, $100 \mathrm{~mm} \mathrm{NaCl}, 1 \%$ SDS, $500 \mu \mathrm{M}$ sodium orthovanadate $(\mathrm{NaV})$, and protease inhibitors]. The extracts were then diluted to a modified RIPA buffer (10 mM Tris, $100 \mathrm{~mm} \mathrm{NaCl}, 0.1 \%$ SDS, $1 \%$ Triton X-100, $500 \mu \mathrm{M} \mathrm{NaV}$, and protease inhibitors), and Ret51 was affinity purified by Ret51 immunoprecipitation. This method allowed for the isolation of Ret without associated adaptor proteins, as determined by phosphotyrosine immunoblotting of this purified Ret51 (data not shown). These purified proteins were mixed together at a concentration of $1-10 \mu \mathrm{g} / \mathrm{ml}$ in PBS containing $500 \mu \mathrm{M}$ $\mathrm{NaV}, 1 \%$ Nonidet P-40, and protease inhibitors. These mixtures were incubated at $4^{\circ} \mathrm{C}$ for $2 \mathrm{~h}$ before Ret immunoprecipitation or IMAC, as described in the figure legends.

Immunoprecipitations. Ret51, Ret9, Cb1-3, CD2AP, Myc and Flag epitope tag immunoprecipitations were performed using conditions identical to our previous study (Tsui-Pierchala et al., 2002a). After the treatments described in the figure legends, the neurons or cell lines were washed twice with ice-cold PBS and were then detergent extracted using an immunoprecipitation (IP) buffer (10 mM Tris, pH 7.4, 10\% glycerol, $1 \%$ Nonidet P-40, protease inhibitors, and $500 \mu \mathrm{M} \mathrm{NaV}$ ). To these cleared extracts, anti-Ret51, anti-Ret9, anti-Cbl-3, or anti-CD2AP was added (10 $\mu \mathrm{l}$; Santa Cruz Biotechnology) along with protein A agarose and protein $\mathrm{G}$ agarose (Invitrogen). After $3 \mathrm{~h}$ of gentle agitation at $4^{\circ} \mathrm{C}$, the immunoprecipitates were then washed three times with IP buffer, and the complexes were prepared for SDS-PAGE by adding $2 \times$ sample buffer (125 mu Tris, pH 6.8, 20\% glycerol, 10\% $\beta$-mercaptoethanol, $4 \%$ SDS, and $0.016 \%$ bromophenol blue) and heating the immunoprecipitates for $5 \mathrm{~min}$ in a boiling water bath. For the immunoprecipitations using Myc and Flag epitope tag antibodies (Cell Signaling Technology and Sigma, respectively), the same IP procedure was followed except that only $5 \mu \mathrm{l}$ of each antibody was used. For transfected HEK293 cells, one confluent well of a six-well culture dish was sufficient for a single condition in an experiment. For immortalized mouse podocytes, a confluent $10 \mathrm{~cm}^{2}$ culture dish was used for each experimental condition.

For the determination of whether Ret and CD2AP interact in podocytes in vivo, glomeruli were purified from adult rat kidneys using a sieving method (Shankland et al., 1996). Purified glomeruli were extracted using the NP-40 containing IP buffer described above, and the insoluble debris were removed by centrifugation. These supernatants were then subjected to Ret9 and Ret51 immunoprecipitation (10 $\mu$ l of each antibody) or to CD2AP immunoprecipitation.

In some cases, whole-cell extracts were analyzed by immunoblotting. The cells were washed twice with cold PBS before extraction. Next, $2 \times$ sample buffer was applied to the cells, and this mixture was scraped into a Microfuge tube using a cell scraper. The extracts were then boiled for 5 $\min$.

Immunoblotting. Immunoblotting experiments were conducted as reported previously (Tsui-Pierchala et al., 2002a). The antibodies for immunoblotting were as follows: anti-phosphotyrosine was used at a 1:3000 dilution (4G10; Millipore), anti-Ret51 and anti-Ret (extracellular domain; anti-ectoRet) are rabbit polyclonal antibodies described previously (Tsui-Pierchala et al., 2002b), and anti-actin was used at a 1:1000 dilution (Santa Cruz Biotechnology). Anti-Cbl-3 was used at a 1:1000 dilution (Orbigen), anti-CD2AP at a 1:200 dilution (Santa Cruz Biotechnology), anti-Myc at a 1:2000 dilution (Cell Signaling Technology), and anti-FLAG at a 1:2000 dilution (Sigma). The blots were blocked using 2\% BSA (phosphotyrosine, Ret51, ectoRet, Cbl-3, and CD2AP antibodies) or $3 \%$ nonfat milk (Myc, FLAG, and actin antibodies) in Tris-buffered saline containing $0.1 \%$ Tween 20 . The blots were developed using SuperSignal chemiluminescent substrates (Thermo Fisher Scientific). In some cases the immunoblots were quantified using ImageJ software (NIH).

Immunofluorescence. Kidneys from rats were fixed overnight in buffered formalin. To determine whether Ret immunostaining colocalizes with CD2AP, we performed double indirect immunofluorescence staining using a goat anti-Ret antibody (1:100; R\&D Systems) and a rabbit polyclonal CD2AP antibody (1:100; Santa Cruz Biotechnology.) This anti-Ret antibody recognizes the extracellular domain of Ret and, therefore, detects both Ret 9 and Ret51. The specificity of this antibody has been confirmed previously (Golden et al., 2003). Anti-goat Alexa Fluor 488 and anti-rabbit Alexa Fluor 594 (Invitrogen) were used to visualize Ret and CD2AP, respectively. All antibodies were diluted in PBS with 2\% BSA. Immunofluorescence stainings were imaged with an Axiovert 200M microscope and an apotome unit (Zeiss), and photos were generated using Axiovision version 4.6.

Sympathetic neuron survival assays. To assess the effect of CD2AP and Cbl-3 on GDNF-dependent survival, cultured sympathetic neurons [4 d in vitro (DIV)] were transfected with the gene of interest along with GFP using LipofectAMINE LTX with the PLUS reagent (Invitrogen). After 

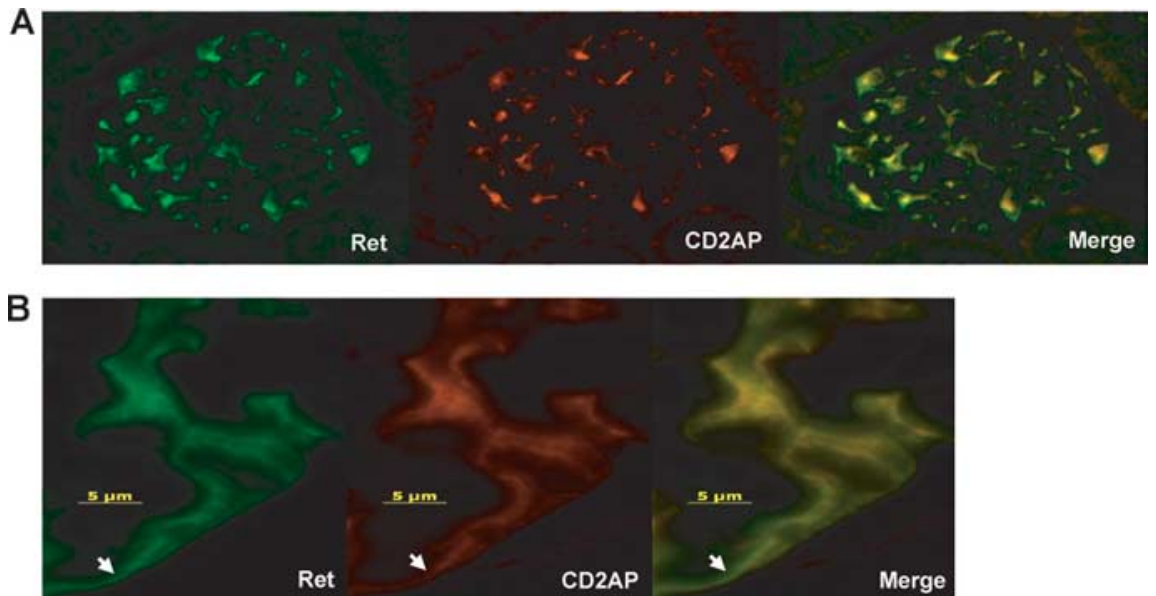

Figure 1. Ret colocalizes with CD2AP within podocytes in glomeruli of the kidney. The glomeruli of normal rat kidneys were immunofluorescently labeled for Ret (green) or CD2AP (red), and the overlapping staining appeared as yellow in the merged image. A, Images of a single glomerulus. Only podocytes, along with their processes, labeled with Ret and CD2AP. B, Highermagnification images of a podocyte with a long process, indicated with the white arrow. The rightmost image shows a composite of both the Ret and the CD2AP immunofluorescence staining.

$48 \mathrm{~h}$, all of the neurons on the culture dish were imaged using a microscope with a scanning stage (Zeiss). The medium was then removed from the neurons, and they were washed twice with medium lacking NGF. The transfected neurons were then given medium containing GDNF (50 ng/ $\mathrm{ml}$ ) and anti-NGF. Two days later, the entire culture dish was again imaged by phase-contrast and GFP fluorescence microscopy. For each condition, the images were compared before and after GDNF application, and the number of surviving cells was counted based on the number of GFP + cells that remained. Neurons were considered alive if their cell bodies were smooth and phase bright (Tsui-Pierchala et al., 2000).

CD2AP and Cbl-3 silencing. CD2AP and Cbl-3 expression was knocked down in sympathetic neurons using small interfering RNA (siRNA), similar to our previous study (Tsui et al., 2006). Control, CD2AP, and Cbl-3 siRNAs (Applied Biosystems/Ambion) were transfected into 4 DIV sympathetic neurons using the i-Fect reagent according to the manufacturer's instructions (Neuromics). Transfection efficiency was determined by the cotransfection of a fluorescently labeled nontargeting, control siRNA (siGLO RISC-free siRNA; Dharmacon RNA Technologies). Immunoblotting of the targeted proteins determined that the maximal knockdown of protein expression was observed $72 \mathrm{~h}$ after siRNA transfection. Greater than $90 \%$ of SCG neurons were transfected, as ascertained by the level of intracellular fluorescence of the siGLO siRNA (see Fig. 9).

\section{Results}

\section{Ret and CD2AP are highly colocalized in podocytes}

Recent experiments indicate that Ret is highly expressed in podocytes, a cell type in the main filtering unit of the kidney known as the glomerulus (Tsui et al., 2006). Podocytes, which are also known as glomerular visceral epithelial cells, are critical in the formation and maintenance of the filtration barrier between blood and urine. Podocytes are postmitotic, morphologically complex cells that have short and long processes, ending in what are called foot processes, which have some similarities to the neuritic extensions of neurons. Part of the filtration barrier between blood and urine created by podocytes is composed of interdigitating foot processes that are linked together by a specialized structure called the slit diaphragm. In podocytes, the expression of Ret, as well as GDNF, is upregulated after their injury in vitro, as well as in animal models of glomerular diseases in vivo (Tsui et al., 2006). GDNF and Ret act as a protective response to podocyte injury, and they support the survival of podocytes in both injured and uninjured states (Tsui et al., 2006).

$\mathrm{CD} 2 \mathrm{AP}$ is an intracellular adaptor molecule that is expressed preferentially in podocytes (Shih et al., 1999; Lehtonen et al., 2008). CD2AP is a constituent of the slit diaphragm (Schwarz et al., 2001; Shih et al., 2001), and inherited mutations in CD2AP are linked to the susceptibility of glomerular disease (Kim et al., 2003). CD2AP knock-out mice have structural abnormalities in foot processes and die of renal failure within 6 weeks of birth (Shih et al., 1999, 2001; Kim et al., 2003). CD2AP, which is homologous to CIN85, interacts with Cbl E3-ligases as well as molecules involved in receptor internalization and endosomal sorting (Kirsch et al., 2001; Petrelli et al., 2002; Soubeyran et al., 2002; Cormont et al., 2003; Kobayashi et al., 2004; Welsch et al., 2005). By linking ubiquitinated proteins to the internalization machinery, CD2AP promotes the downregulation and degradation of activated RTKs (Hicke, 2001; Petrelli et al., 2002; Soubeyran et al., 2002; Kobayashi et al., 2004). To begin to examine whether CD2AP is a regulator of Ret, the localization of both Ret and CD2AP was examined in podocytes in vivo. As expected, both Ret and CD2AP were expressed selectively in podocytes in the glomeruli of adult rats (Fig. 1). CD2AP and Ret were localized to the processes of the podocytes, and a high degree of colocalization between them was observed (Fig. 1). The examination of glomeruli using the apotome unit of the microscope, which produces near-confocal images, confirmed that these two molecules were indeed highly colocalized in podocytes (Fig. $1 B$ ). These data suggest that Ret and CD2AP interact in podocytes in vivo.

\section{CD2AP associates with inactive Ret and dissociates from activated Ret}

The morphologic similarities between podocytes and neurons, and the importance of CD2AP in the downregulation of RTKs, prompted us to investigate whether CD2AP is involved in the downregulation of Ret. To determine whether CD2AP and Ret associate with each other, immunoprecipitation experiments were conducted in primary sympathetic neurons. Neurons were treated with medium alone, as a negative control, or with GDNF. The cells were then detergent extracted, and Ret was immunoprecipitated. CD2AP immunoblotting of these immunoprecipitates revealed that $\mathrm{CD} 2 \mathrm{AP}$ was associated with Ret under basal, unstimulated conditions, and that CD2AP dissociated from Ret after Ret activation by GDNF (Fig. 2A). The association between Ret and CD2AP under basal conditions, but not during Ret activation, was also observed in sympathetic neurons if CD2AP was immunoprecipitated and these immunoprecipitates were subjected to Ret immunoblotting (Fig. $2 B$ ). To determine whether the association between CD2AP and Ret was observed in other cell types, immortalized mouse podocytes were subjected to immunoprecipitation experiments. Similar to sympathetic neurons, Ret and CD2AP were associated under basal conditions, but dissociated after Ret activation in podocytes (Fig. 2C).

NGF inhibits the downregulation of Ret after GDNFdependent activation by inhibiting the internalization and polyubiquitination of Ret (Pierchala et al., 2007). To determine whether NGF inhibits Ret51 degradation by altering the association of CD2AP to Ret51, mature sympathetic neurons were stimulated with GDNF or medium alone, either in the presence or 
absence of NGF. NGF had no effect on the association of CD2AP with Ret or on the dissociation of CD2AP from activated Ret (Fig. 2B). NGF, therefore, does not act to stabilize activated Ret by somehow altering the association between CD2AP and Ret51. Together, these data indicate that CD2AP associates with Ret under basal, unstimulated conditions, and dissociates with Ret after its activation in both neurons and podocytes.

To determine whether Ret and CD2AP are associated with each other in vivo, the glomeruli of kidneys were examined. Podocytes, which selectively express both Ret and CD2AP, are only present in the glomerulus. Glomeruli were purified from rodent kidneys, and the extent of Ret and CD2AP interaction was ascertained by coimmunoprecipitation studies. The majority of Ret expressed in podocytes, the only glomerular cell type that expresses Ret (Tsui et al., 2006), was associated with CD2AP (Fig. 2 D, top). Although CD2AP was associated with Ret when Ret was immunoprecipitated from glomeruli, there was a significant amount of CD2AP that was not bound to Ret (Fig. $2 D$, bottom). Therefore, Ret and CD2AP are associated with each other in podocytes in vivo.

\section{GDNF and NGF regulate the association of Cbl-3 with Ret and CD2AP}

To better understand how NGF and GDNF regulate Ret downregulation, we sought to identify the E3-ligases that ubiquitinate Ret. The Cbl family of E3-ligases, which consists of c-Cbl, Cbl-b, and Cbl-c/ Cbl-3, catalyze the ubiquitination of activated RTKs (Dikic and Giordano, 2003; Swaminathan and Tsygankov, 2006). In sympathetic neurons, we examined whether Cbl-3 associated with Ret using the biochemical approach just described. Under unstimulated conditions, Cbl-3 was associated with Ret in sympathetic neurons (Fig. $3 A, B)$. When Ret was activated by GDNF, Cbl-3 dissociated from Ret (Fig. $3 A, B$ ). Cbl E3-ligases typically do not bind to inactive RTKs. Instead, they associate with activated receptors via the interaction of their tyrosine kinase-binding (TKB) domain with a phosphotyrosine residue in the target receptor. Because Cbl-3 displays an unconventional pattern of association with Ret, it is not likely that Cbl-3 binds to Ret via its TKB domain. To determine whether NGF alters this interaction between Ret and Cbl-3, mature sympathetic neurons were exposed to NGF, or medium alone, before Ret activation with GDNF. Interestingly, NGF completely blocked the dissociation of Cbl-3 from Ret when Ret was activated with GDNF (Fig. $3 A, B$ ). In sympathetic neurons, c-Cbl is not detected in Ret51 immunoprecipitates (Pierchala et al., 2006). Although Cbl-b does associate with Ret in neurons (Pierchala et al., 2006), Cbl-b is not regulated by NGF (data not shown). Therefore, Cbl-3 appears to be unique among the $\mathrm{Cbl}$ family of E3-ligases in that its interaction with Ret is regulated by both GDNF and NGF.

The observation that Cbl-3 had a pattern of association with
B

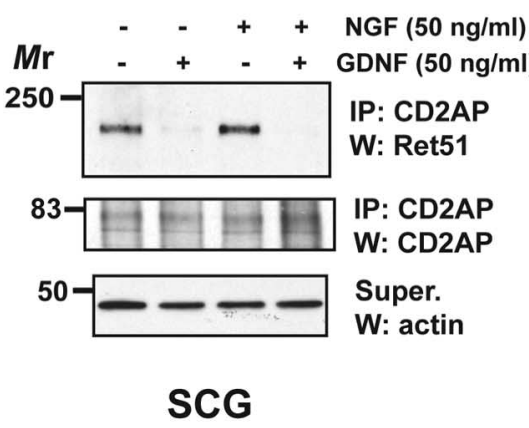

D

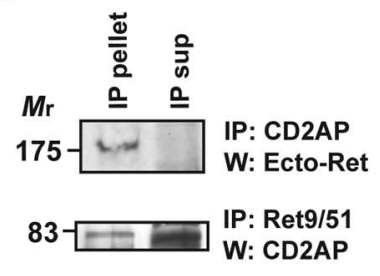

Glomeruli

Figure 2. CD2AP associates with inactive Ret and dissociates from ligand-activated Ret. Cells were given medium alone or medium containing GDNF ( $50 \mathrm{ng} / \mathrm{ml}$ ) for $15 \mathrm{~min}$. The cells were then detergent extracted, and Ret was immunoprecipitated from

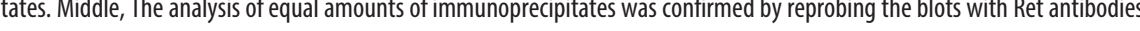
analyzed by Ret immunoblotting. Mature sympathetic neurons were analyzed in $\boldsymbol{A}$ and $\boldsymbol{B}$, and immortalized mouse podocytes were analyzed in $C$. The effect of GDNF on the dissociation of CD2AP from Ret was also compared between mature sympathetic precipitates were then analyzed by CD2AP or Ret immunoblotting, respectively. These experiments were performed two to four times with similar results. W, Western blot.

inactive and active Ret51 that is identical to CD2AP suggests that CD2AP and Cbl-3 may interact with each other. To test this hypothesis, sympathetic neurons were stimulated with GDNF or with medium alone, and Cbl-3 was immunoprecipitated from their detergent extracts. CD2AP Western analysis of these immunoprecipitates demonstrated that CD2AP and Cbl-3 associated modestly under unstimulated conditions (Fig. 4A). Interestingly, although both CD2AP and Cbl-3 dissociated from activated Ret (Figs. 2, 3), the interaction between CD2AP and Cbl-3 increased after Ret activation by GDNF (Fig. 4A). The enhanced association of CD2AP with Cbl-3 after Ret activation was also observed when CD2AP was immunoprecipitated and these complexes were subjected to Cbl-3 immunoblotting (Fig. $4 B$ ).

To determine whether NGF altered the interaction between CD2AP and Cbl-3, as it did the dissociation of Cbl-3 from Ret, mature sympathetic neurons were stimulated with NGF or with medium alone before Ret activation with GDNF. NGF inhibited the association of CD2AP with Cbl-3 that was induced by GDNF (Fig. 4A,B). NGF also inhibited the basal level of interaction between CD2AP and Cbl-3 that was observed without GDNF stimulation (Fig. 4A,B). Together, these data suggest that CD2AP and Cbl-3 associate with Ret51 under basal conditions and, after Ret activation, both CD2AP and Cbl-3 dissociate with 


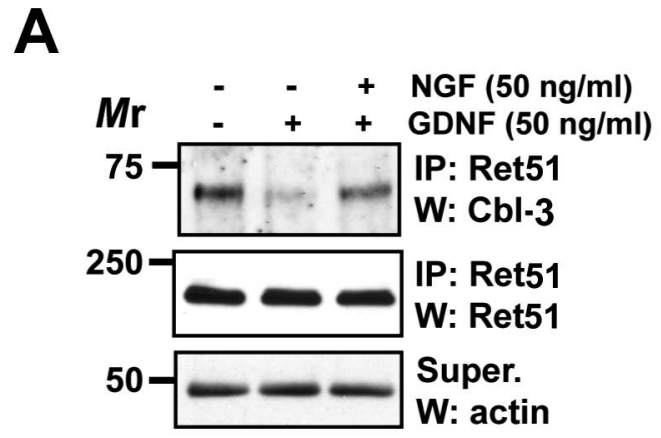

B

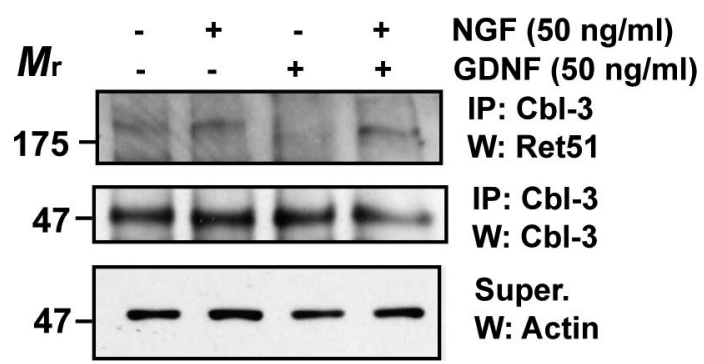

Figure 3. Cbl-3 associates with Ret in a GDNF-dependent and NGF-dependent manner. Mature sympathetic neurons were maintained in NGF $(50 \mathrm{ng} / \mathrm{ml})$ or deprived of NGF for $2 \mathrm{~d}$. These neurons were then exposed to $\mathrm{GDNF}(50 \mathrm{ng} / \mathrm{ml})$ or medium alone for $15 \mathrm{~min}$. Detergent extracts were produced from the neurons, and these extracts were then analyzed by either Ret51 immunoprecipitation ( $\boldsymbol{A})$ or $\mathrm{Cbl}-3$ immunoprecipitation $(\boldsymbol{B})$. The association of $\mathrm{Cbl}-3$ to Ret51 was determined in a manner similar to the experiments in Figure 2. These experiments were performed two to three times with similar results. Super., Supernatant; W, Western blot.

Ret. During their dissociation from activated Ret, CD2AP and Cbl-3 associate with each other. Importantly, NGF completely inhibited the GDNF-induced association of CD2AP with Cbl-3, while at the same time inhibiting the dissociation of Cbl-3 from activated Ret (Fig. $3 A, B$ ). These data suggest that these two processes, the dissociation of CD2AP and Cbl-3 from activated Ret and the interaction of CD2AP with Cbl-3, are linked mechanistically. Furthermore, these two events may represent the point at which NGF blocks the downregulation of activated Ret.

\section{CD2AP associates with Ret via a direct interaction}

CD2AP is known to be associated with autophosphorylated RTKs indirectly via binding of CD2AP to Cbl-family E3 ligases that are directly associated with the autophosphorylated receptor (Kirsch et al., 2001; Kobayashi et al., 2004). Our observation that CD2AP dissociated from Ret after its activation suggests that CD2AP associates with inactive Ret by some other means. We first tested the hypothesis that CD2AP binds directly to Ret. Recombinant GST-tagged CD2AP was expressed in bacteria and purified under native conditions using glutathione-agarose. Ret51, or Ret51 harboring a K758M mutation that renders it kinase-dead, was purified from transfected HEK293 cells under denaturing conditions. This allowed for the isolation of Ret in the absence of associated adaptor proteins that may bind to Ret when overexpressed in HEK293 cells, which was confirmed by phosphotyrosine immunoblotting of the purified Ret (data not shown). Purified CD2AP was then mixed and allowed to bind to Ret51, or kinase-dead Ret51 (KDR51). CD2AP associated with both Ret51 and KDR51 (Fig. 5A). When Ret51 is expressed in HEK293 cells, it becomes highly autophosphorylated and activated in the absence of ligand
A
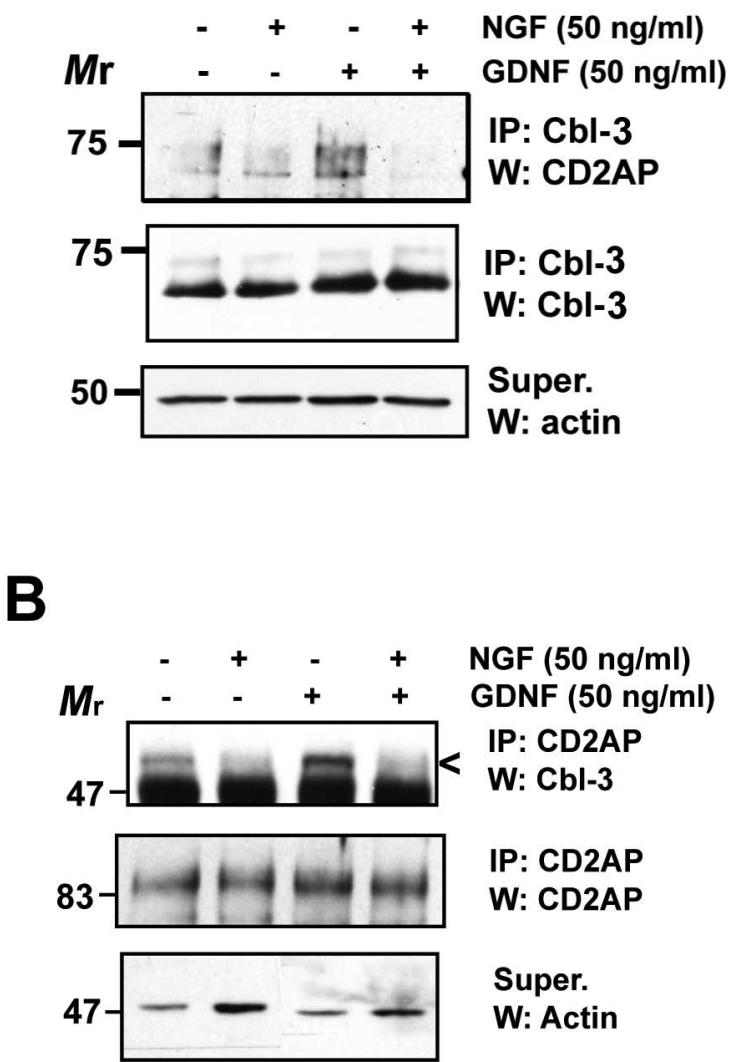

Figure 4. NGF inhibits the interaction between $C D 2 A P$ and $\mathrm{Cbl}-3$. Mature sympathetic neurons that were maintained in NGF ( $50 \mathrm{ng} / \mathrm{ml})$ or medium alone were stimulated with GDNF (50 $\mathrm{ng} / \mathrm{ml}$ ) for $15 \mathrm{~min}$. The association of CD2AP with $\mathrm{Cbl}-3$ was analyzed by $\mathrm{Cbl}-3(\boldsymbol{A})$ and $\mathrm{CD} 2 \mathrm{AP}(\boldsymbol{B})$ immunoprecipitations followed by immunoblotting for $C D 2 A P$ and $C b l-3$, respectively. These analyses were performed in a manner similar to the experiments in Figure 2. $\boldsymbol{B}$, Top, The arrowhead indicates the position of $\mathrm{Cbl}-3$, which migrates just above the lgG heavy chain. Actin immunoblotting again served as a control for the examination of similar amounts of extracts. These experiments were performed three times with similar results. Super., Supernatant; W, Western blot.

stimulation (data not shown). CD2AP associated with this autophosphorylated Ret to an extent similar to its association to KDR51 (Fig. 5A). These data indicate that CD2AP binds directly to Ret independently of the autophosphorylation status of Ret. This conclusion suggests that the dissociation of CD2AP from activated Ret in neurons is caused by other, unidentified signaling molecules.

To determine whether the association of CD2AP with Ret51 is altered by the phosphorylation status of Ret in non-neuronal cells, coexpression studies were conducted in HEK293 cells. Ret51 or KDR51 was coexpressed with CD2AP, and their association was then assessed by coimmunoprecipitation experiments. Interestingly, CD2AP did not interact with autophosphorylated Ret51, but it readily associated with unphosphorylated Ret51 (KDR51) (Fig. 5B). By comparing the coprecipitated CD2AP: Ret51 ratios, we found that coexpression of Cbl-3 with CD2AP did not abolish the interaction of CD2AP with KDR51. However, their coexpression caused a significant loss of Ret51, presumably because of degradation (Fig. $5 B$ ). Together, these data indicate that CD2AP associated directly with Ret51, regardless of its autophosphorylation status, and that CD2AP does not require Cbl-3 for this association. In surprising contrast, in intact cells, CD2AP association with autophosphorylated Ret is inhibited. This sug- 
A

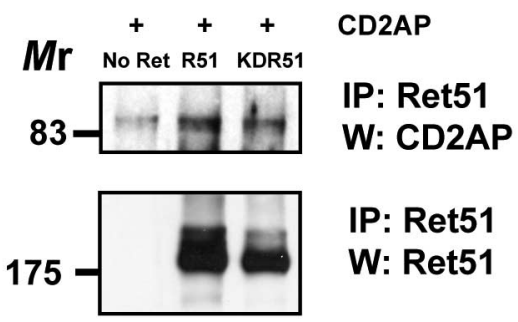

B

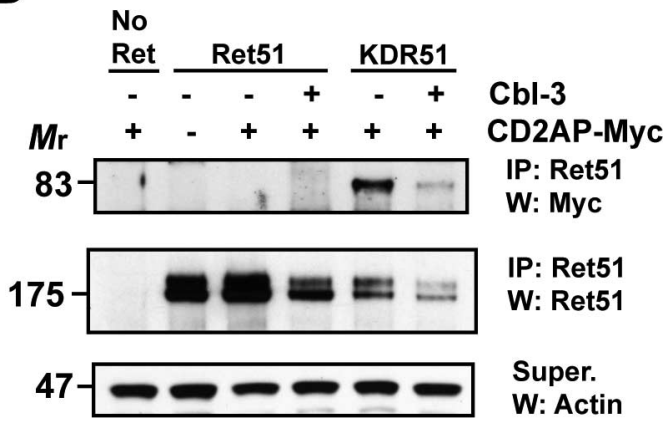

Figure 5. CD2AP interacts directly with Ret. A, Purified, activated Ret51 (R51), inactive, kinase-dead Ret51 (KDR51), or neither protein (No Ret) was mixed with purified CD2AP in vitro. Top, Ret was immunoprecipitated, and the extent of CD2AP binding was determined by CD2AP immunoblotting. Bottom, The amount of Ret51 in each sample was determined by reprobing these blots with anti-Ret51. B, HEK293 cells were transfected with Ret51 or KDR51 in the presence of myc-tagged CD2AP, flag-tagged Cbl-3, both, or neither (indicated above the panels). Ret51 was then immunoprecipitated, and the precipitates were subjected to Myc-tag immunoblotting. The amount of Ret51 in each sample was determined by reprobing these blots with anti-Ret51. The relative amount of protein in each sample was confirmed by actin immunoblotting. These experiments were performed two to three times with similar results. Super., Supernatant; W, Western blot.

gests that either CD2AP is displaced from Ret by an adaptor protein that binds with higher affinity to activated Ret than CD2AP does, or that another molecule inhibits the association of CD2AP with activated Ret.

\section{Cbl-3 binds directly to both Ret and CD2AP}

To examine whether Cbl-3 associates directly with Ret, purified, recombinant 6-His-Cbl-3 was mixed with purified Ret51 or KDR51. The interaction between these purified proteins was then determined by Ret51 immunoprecipitation and immunoblotting for Cbl-3, similar to the analysis of CD2AP in Figure 5A. Cbl-3 associated with activated Ret51 and inactive Ret51 to a similar extent (Fig. 6A). There was no apparent difference between the short and long isoforms of Cbl-3 in terms of their affinity for Ret. The purified Cbl-3 proteins did not associate nonspecifically with the immobilized Ret51 antibody, confirming the specificity of their interaction (Fig. 6A). These data indicate that Cbl-3 associates directly to Ret regardless of its phosphorylation status.

The observation that Cbl-3 is capable of binding to both autophosphorylated and unphosphorylated Ret51 (Fig. 6A) suggests that Cbl-3 does not associate with Ret via its TKB domain, which binds selectively to phosphotyrosine residues. To determine which protein domain in Cbl-3 binds to Ret, we expressed point mutants of Cbl-3 along with Ret51 in HEK293 cells, which do not express Ret endogenously. The transfected Cbl-3 associ- ated with both kinase-dead Ret and wild-type Ret (Fig. 6B). As anticipated, a mutant form of Cbl-3, G276E Cbl-3, which has dramatically impaired binding of the TKB domain to phosphotyrosine residues, still associated with Ret (Fig. $6 B$ ). In surprising contrast, a mutation in the ring finger domain of Cbl-3, C351A, which inactivates the E3 ligase activity of Cbl-3, abolished its binding to Ret (Fig. $6 \mathrm{~B}$ ). Consistent with both of these results, a truncated version of Cbl-3 that removes the C-terminal ring finger and proline-rich domain, Cbl-3 TKB, did not bind to Ret51 (Fig. $6 \mathrm{~B}$ ). These results indicate that the association of Cbl-3 with Ret requires a functional ring finger domain in $\mathrm{Cbl}-3$, and not the TKB domain.

To determine whether the interaction between Cbl-3 and $\mathrm{CD} 2 \mathrm{AP}$ is direct, or mediated through an intermediate protein such as Ret, in vitro binding studies were performed using purified proteins. Purified CD2AP associated directly to Cbl-3, but not the purification resin (Fig. $6 C$ ), suggesting that the interaction between CD2AP and Cbl-3 represents a direct association between them. These data described in the last several figures indicate that CD2AP and Cbl-3 are associated directly with Ret when Ret is inactive, and that CD2AP and Cbl-3 dissociate from Ret, most likely as a complex, when Ret is activated. Because CD2AP and Cbl-3 both are capable of associating with autophosphorylated Ret in vitro, the dissociation of the CD2AP and Cbl-3 from Ret likely occurs either as a consequence of their mutual association or via their displacement by Ret adaptors that have a higher affinity for phosphorylated Ret.

Because Ret9 and Ret51 are degraded with markedly different kinetics (Scott et al., 2005; Pierchala et al., 2006), we tested whether there is a difference in the association between Cbl-3 and CD2AP with these Ret isoforms. When Ret9 or Ret51 was coexpressed with CD2AP in HEK293 cells, CD2AP associated with both Ret9 and Ret51 (Fig. 6D). Cbl-3 was also capable of associating with both Ret9 and Ret51 in transfected cells (Fig. 6D). Although Ret51 is the predominant isoform of Ret expressed in sympathetic neurons, Ret9 is also expressed at lower levels and associated with both CD2AP and Cbl-3, similar to Ret51 (Fig. $6 E)$. Whether the difference in the rate of degradation between Ret9 and Ret51 after ligand stimulation is attributable to the differential association or regulation of CD2AP or Cbl-3 will require a more detailed investigation.

\section{CD2AP controls whether Cbl-3 inhibits or promotes Ret degradation}

The association of CD2AP and Cbl-3 with Ret, as well as with each other, suggests that they trigger the ubiquitination and internalization of Ret, leading to its degradation. To determine whether CD2AP and Cbl-3 alter the degradation kinetics of activated Ret, HEK293 cells were transfected with Ret51, or Ret51 along with CD2AP. These cells were then exposed to cycloheximide (CHX) for various lengths of time, and the amount of Ret51 was determined at each time point by immunoblotting (Fig. 7). The application of $\mathrm{CHX}$ inhibits protein synthesis, thus allowing the rate of Ret turnover to be observed. Ret was rapidly turned over, with the majority of Ret being degraded within $24 \mathrm{~h}$ (Fig. $7 A, B)$. This degradation process was initiated by Ret autophosphorylation because kinase-dead Ret51, when expressed in HEK293 cells, was not rapidly degraded (data not shown). Coexpression of CD2AP with Ret51 only modestly enhanced the degradation of Ret51 (Fig. 7A-C). Remarkably, coexpression of Cbl-3 led to an almost complete inhibition of Ret51 degradation, even as long as $24 \mathrm{~h}$ after CHX exposure (Fig. 7A-C). The inhibitory effect of Cbl-3 on Ret turnover is in stark contrast to the 
A

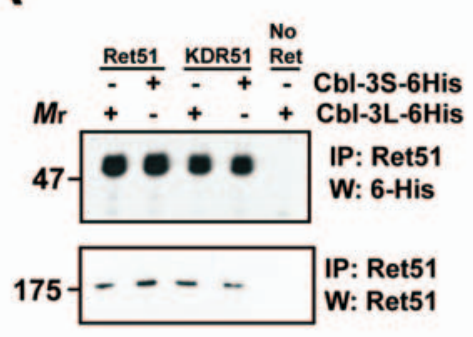

D

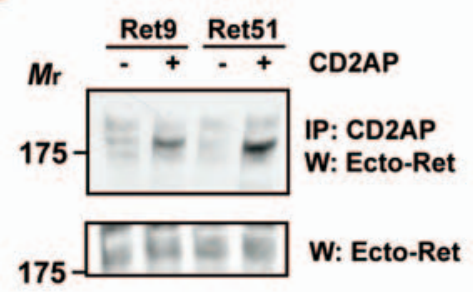

B

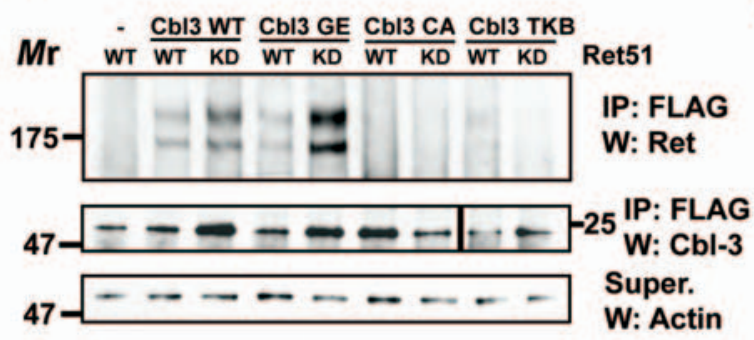

C

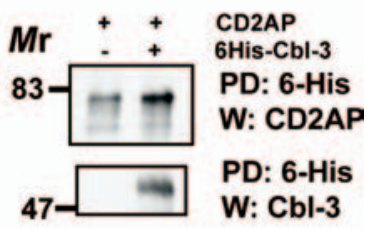

E

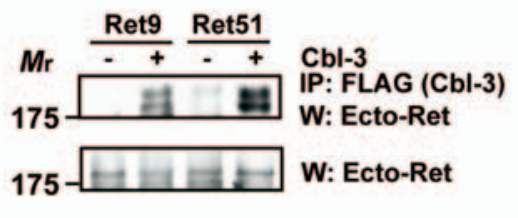

Figure 6. Cbl-3 interacts directly with both Ret and CD2AP.A, Purified Ret51, kinase-dead Ret51 (KDR51), or neither was incubated with purified 6-His-tagged Cbl-3S or Cbl-3L in vitro. The extent of (bl-3 association with Ret51 was assessed by Ret immunoprecipitations performed identical to those in Figure 5A. B, HEK293 cells were transfected with Ret51 (WT) or kinase-dead Ret51 (KD) along with Cbl-3 (WT), Cbl-3 G276E (GE), Cbl-3 C351A (CA), or only the TKB domain of Cbl-3 (TKB). The transfected cells were then detergent extracted, and the transfected Cbl-3 proteins were immunoprecipitated with anti-Flag (all (bl-3 proteins were Flag-tagged). The immunoprecipitates were analyzed first by Ret immunoblotting (top) and subsequently by (bl-3 immunoblotting of the stripped blots (middle). Because the truncated form of Cbl-3 containing only the TKB domain is considerably smaller than the other Cbl-3 proteins, the molecular weight marker pertaining to this protein is indicated to the right of the blot. Bottom, Actin immunoblotting confirmed the analysis of similar amounts of protein. C, Purified 6-His-Cbl-3L was incubated with purified CD2AP or with buffer alone. Cbl-3 was then subjected to pull-down (PD) assays using immobilized metal ion chromatography. These precipitates were analyzed first by CD2AP immunoblotting (top), and the blots were then stripped and reprobed with (bl-3 antibodies (bottom). D, Ret9 or Ret51 was expressed alone or with CD2AP (left) or Cbl-3 (right). CD2AP was then immunoprecipitated from these extracts and the association of Ret9 or Ret51 ascertained by immunoblotting with an antibody to the extracellular domain of Ret (Ecto-Ret). Likewise, Cbl-3 was immunoprecipitated using FLAG antibodies, and the extent of Ret 9 and Ret51 binding was determined by immunoblotting with Ecto-Ret antibodies. Bottom, Similar amounts of Ret expression were confirmed by immunoblotting the extracts with anti-Ecto-Ret. $\boldsymbol{E}$, The extent of CD2AP and Cbl-3 binding to Ret9 and Ret51 in sympathetic neurons was determined using methods similar to those in $\boldsymbol{D}$. In this case, either Ret9 or Ret51 were immunoprecipitated, and these precipitates were evaluated by CD2AP or Cbl-3 immunoblotting. These experiments were performed two to three times with similar results. Super., Supernatant; $W$, Western blot.

degradation-stimulating effects of c-Cbl and Cbl-b on RTK turnover (Dikic and Giordano, 2003; Swaminathan and Tsygankov, 2006). To determine whether CD2AP acts upstream of Cbl-3, $\mathrm{CD} 2 \mathrm{AP}$ and Cbl-3 were coexpressed with Ret51. Remarkably, CD2AP not only blocked the inhibitory effect of Cbl-3 on Ret degradation, but their coexpression induces a more rapid degradation of Ret51 compared with when Ret51 was expressed alone or when expressed with CD2AP (Fig. $7 B, C$ ). These data suggest that $\mathrm{CD} 2 \mathrm{AP}$ modulates the function of $\mathrm{Cbl}-3$, converting it from an inhibitor of Ret degradation to a promoter of Ret degradation.

To explore whether the inhibition of CD2AP or Cbl-3 impairs activation-mediated Ret degradation, a dominant-inhibitory form of both CD2AP and Cbl-3 was used. A truncated form of CD2AP, CD2AP 1-327, lacks the C-terminal half of the molecule that mediates endosomal trafficking (Cormont et al., 2003). Consequently, truncated forms of CD2AP block the ligand-induced degradation of PDGF receptors (Cormont et al., 2003). The expression of CD2AP 1-327 in HEK293 cells, along with Ret51, resulted in the inhibition of Ret51 degradation (Fig. $7 B, C$ ), suggesting that CD2AP is required for Ret51 downregulation. The C351A point mutation within the ring finger domain of Cbl-3 abolishes its E3 ligase activity (Kim et al., 2004). This point mutation also eliminated the binding of Cbl-3 to Ret (Fig. 6). To determine whether the expression of Cbl-3 C351A altered the kinetics of Ret51 downregulation, HEK293 cells, which do not endogenously express Cbl-3 (Kim et al., 1999), were transfected with Cbl-3 C351A along with Ret51. Cbl-3 C351A did not inhibit
Ret51 degradation, compared with the inhibitory effect of Cbl-3 (Fig. $7 \mathrm{~B}, \mathrm{C}$ ). In conclusion, $\mathrm{CD} 2 \mathrm{AP}$ is required for Ret downregulation, and Cbl-3 likely functions as a rheostat that controls the rate of Ret turnover, switching back and forth between inhibition and acceleration of Ret degradation.

Cbl-3 and CD2AP regulate the potency of the survival effects of GDNF on sympathetic neurons

The observation that $\mathrm{CD} 2 \mathrm{AP}$ and $\mathrm{Cbl}-3$ regulate the degradation of Ret suggests that they control the duration of Ret signaling and, therefore, the survival potency of GFLs. To test this hypothesis, we examined the ability of GDNF to support the survival of sympathetic neurons when CD2AP and Cbl-3 levels and function were altered. Primary sympathetic neurons were transfected with GFP alone or with GFP and CD2AP, CD2AP 1-328, Cbl-3, Cbl-3 $\mathrm{C} 351 \mathrm{~A}$, or both CD2AP and Cbl-3. The neurons were given $24 \mathrm{~h}$ to express the transfected cDNAs, and were then deprived of NGF and simultaneously given GDNF (50 ng/ml). After $2 \mathrm{~d}$ in the presence of GDNF, the number of surviving, GFP + neurons was determined. GDNF supported the survival of $50.7 \%$ of transfected neurons (Fig. 8), similar to the survival rate previously reported for rat sympathetic neurons (Pierchala et al., 2006). The overexpression of CD2AP decreased significantly the number of neurons that could be supported by GDNF to $40.8 \%$ (Fig. 8). Expression of CD2AP 1-328, in contrast to CD2AP, enhanced significantly the survival-promoting activity of GDNF to $62.6 \%$ (Fig. 8). The overexpression of Cbl-3 augmented significantly the 

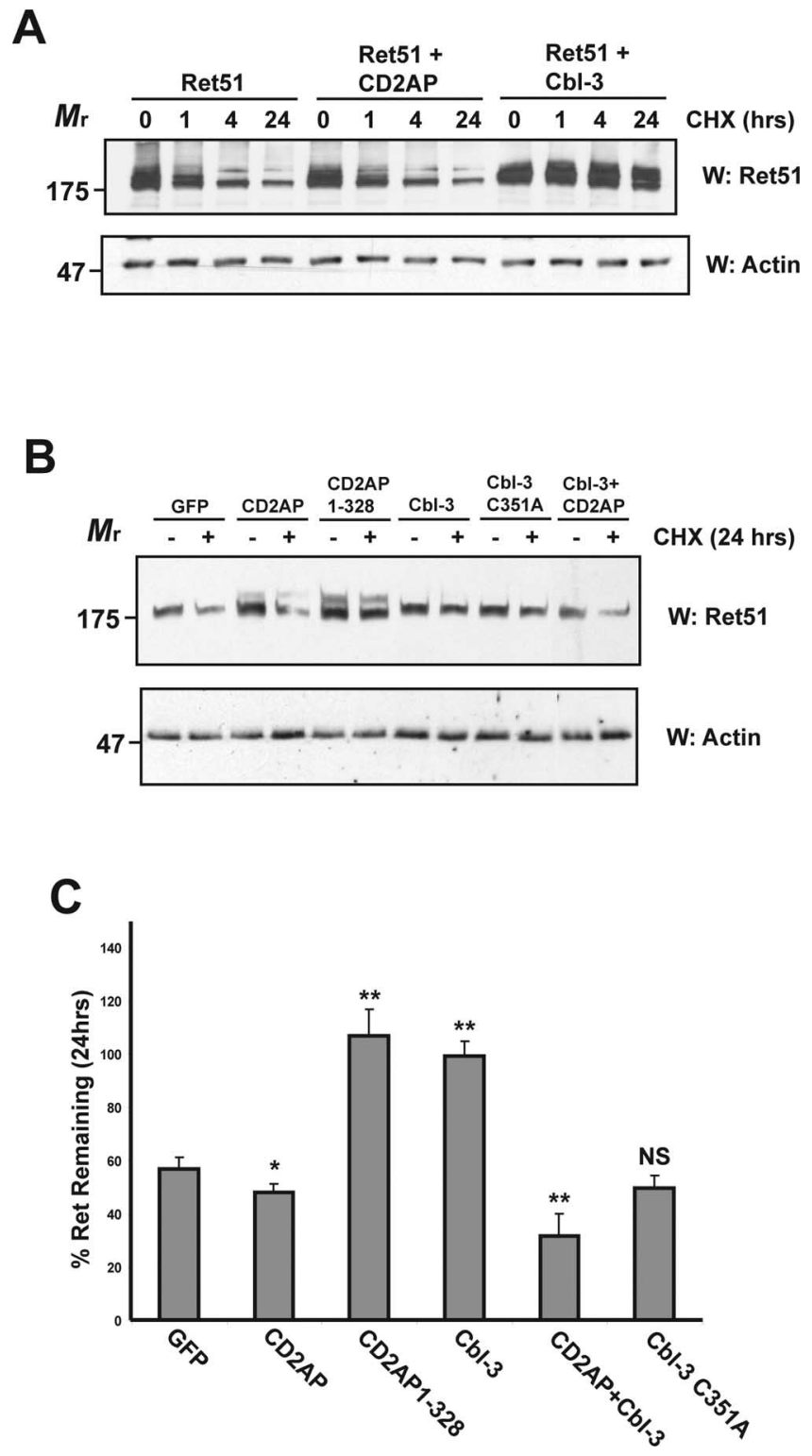

Figure 7. Cbl-3 controls Ret degradation in a CD2AP-dependent manner. A, HEK293 cells were transiently transfected with Ret51 alone, Ret51 and CD2AP, or Ret51 and Cbl-3. After $24 \mathrm{~h}$, the cells were exposed to $\mathrm{CHX}$ for various lengths of time, and thereafter were harvested for the analysis of total cellular proteins. Ret turnover was examined by Ret immunoblotting these whole cell extracts, and actin immunoblotting served as a control for the amount of protein analyzed in each condition. $\boldsymbol{B}$, Ret turnover was examined as in $\boldsymbol{A}$ with a $24 \mathrm{~h}$ CHX application only. Ret was again transfected alone or with $C D 2 A P, C b l-3$, both CD2AP and $C b l-3$, or mutants of $\mathrm{CD} 2 \mathrm{AP}$ and $\mathrm{Cbl}-3$ (indicated above the blot). These experiments were performed three times with similar results. $\boldsymbol{C}$, The results in $\boldsymbol{B}$ were quantified using ImageJ software (NIH). The error bars represent SEM. Asterisks indicate that there was a significant difference when compared with Ret51 alone, as follows: ${ }^{*} p<0.05 ;{ }^{* *} p<0.01$; NS, no statistically significant difference. The amount of Ret degraded when CD2AP was coexpressed was also significantly different from when Ret was coexpressed with both CD2AP and Cbl-3 $(p<0.05)$. W, Western blot.

GDNF-dependent survival of sympathetic neurons to $69.6 \%$, in contrast to Cbl-3 C351A, which did not alter the efficacy of GDNF on neuronal survival (Fig. 8). The overexpression of both $\mathrm{CD} 2 \mathrm{AP}$ and Cbl-3 in neurons caused a marked reduction in the ability of GDNF to support their survival (29.4\%) (Fig. 8), consistent with the enhanced Ret degradation induced by the coexpression of CD2AP and Cbl-3 (Fig. 7). The effects of CD2AP and Cbl-3 on Ret survival signaling coincide with their effects on Ret turnover in HEK293 cells (Fig. 7). These data indicate that

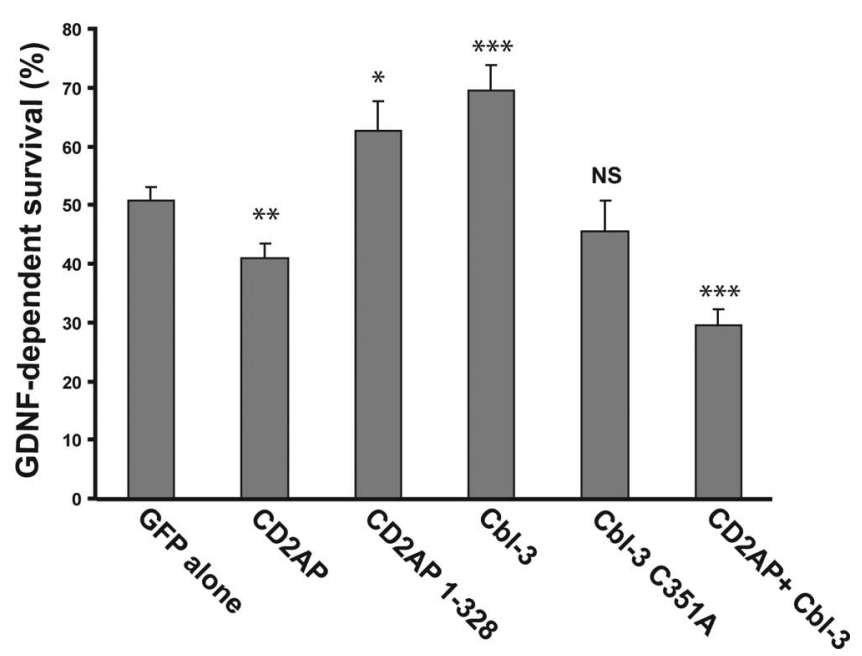

Figure 8. $\quad \mathrm{CD} 2 \mathrm{AP}$ and $\mathrm{Cbl}-3$ regulate neuronal survival mediated by GDNF. Primary sympathetic neurons ( 4 DIV) were transiently transfected with GFP alone, or with GFP and CD2AP, the $\mathrm{N}$-terminal 328 residues of CD2AP (CD2AP 1-328), Cbl-3, Cbl-3 C315A, or both CD2AP and Cbl-3. Twenty-four hours after transfection, the neurons were deprived of NGF and given GDNF (50 $\mathrm{ng} / \mathrm{ml}$ ). After $2 \mathrm{~d}$ in GDNF, the number of surviving GFP + neurons was determined as described in the Materials and Methods. Multiple dishes were analyzed from three independent experiments. Error bars represent SEM. Conditions in which the percentage of surviving neurons were significantly different from neurons transfected with GFP alone were indicated as follows: ${ }^{*} p<$ $0.05 ;{ }^{* *} p<0.01 ;{ }^{* * *} p<0.001$; NS, no statistically significant difference between the two datasets.

CD2AP and Cbl-3 are capable of modulating the rate of Ret51 turnover and GFL potency.

To determine whether CD2AP and Cbl-3 are endogenous, physiologic regulators of Ret downregulation and signal transduction, CD2AP and Cbl-3 were silenced in sympathetic neurons. To achieve this, a nonspecific siRNA or siRNAs to Cbl-3, $\mathrm{CD} 2 \mathrm{AP}$, or both were transfected into primary sympathetic neurons. We were able to transfect $>90 \%$ of the neurons with the siRNAs, as determined by cotransfection of a nonsilencing, fluorescently tagged RNA (Fig. 9A). The effectiveness of the gene silencing was determined by immunoblotting cellular extracts produced from sympathetic neurons $72 \mathrm{~h}$ after their transfection with increasing concentrations of siRNAs. The maximal knockdown of Cbl-3, CD2AP, and both Cbl-3 and CD2AP occurred when a total concentration of 50 nM RNA was used (Fig. 9B). We did not achieve a complete knockdown of CD2AP, or Cbl-3 and CD2AP when silenced together (Fig. 9B), even though three different siRNAs to each gene were transfected simultaneously. Nevertheless, the knockdown of Cbl-3 and CD2AP affected significantly GDNF-activated Ret degradation. Silencing of CD2AP inhibited the degradation of Ret after its activation (Fig. 9C). The simultaneous knockdown of Cbl-3 and CD2AP further inhibited Ret degradation (Fig. 9C). The nearly complete knockdown of only Cbl-3, in contrast, did not alter the degradation of Ret after activation with GDNF for $8 \mathrm{~h}$ (Fig. 9C). These results suggested that CD2AP was required for Ret degradation after ligand activation. On the other hand, a decrease in Cbl-3 expression only affected the rate of Ret degradation in combination with CD2AP downregulation (Fig. 9C). These observations suggest that there may be other E3-ligases in addition to Cbl-3 that can regulate Ret degradation, or that the incomplete knockdown of Cbl-3 is not sufficient for inhibition of its activity. It is also likely that Ret degradation initiated by Cbl-3 is regulated by other components of the degradation machinery, such as CD2AP.

To test whether a physiologic function of Cbl-3 and CD2AP is 

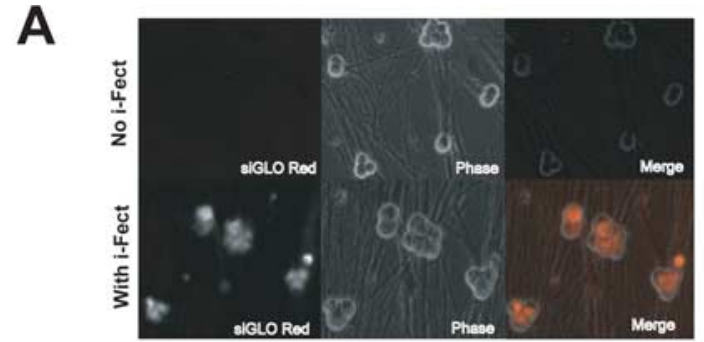

B

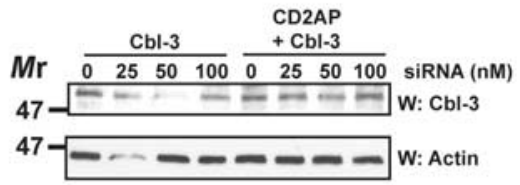

C

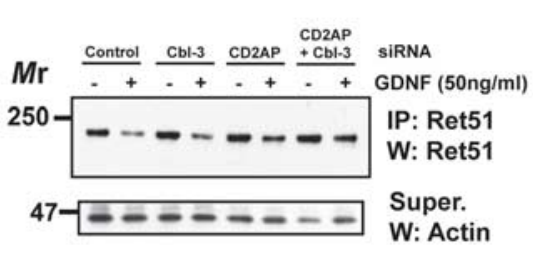

D

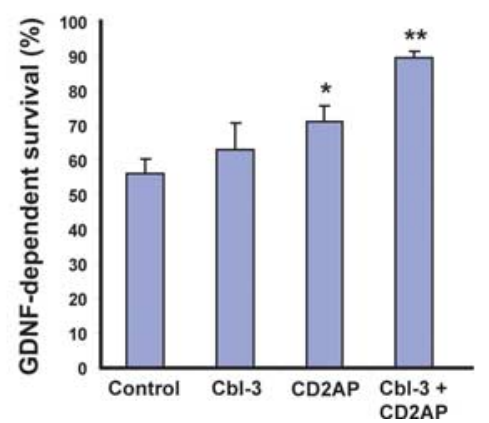

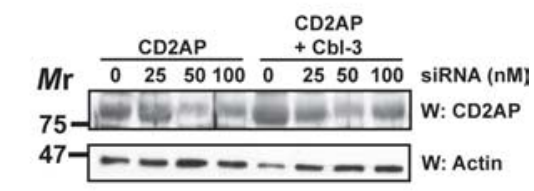
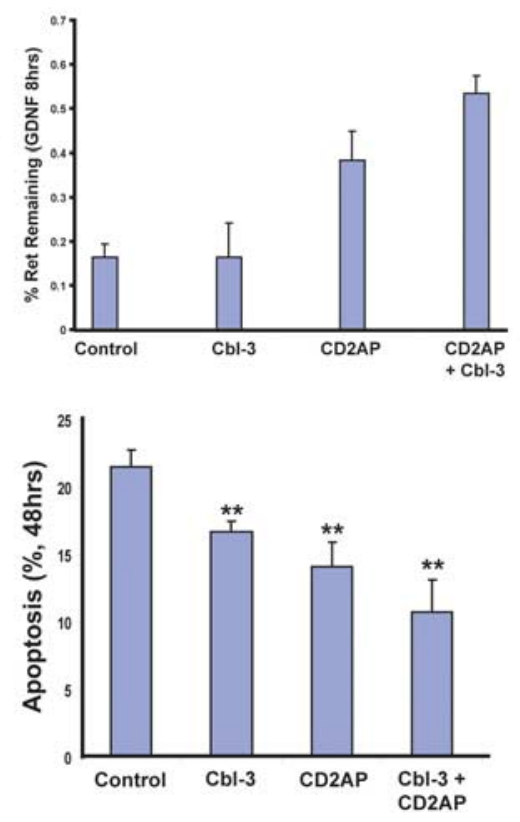

Figure 9. $\quad \mathrm{CD} 2 \mathrm{AP}$ and $\mathrm{Cbl}-3$ modulate Ret51 degradation and GFL potency in sympathetic neurons. $\boldsymbol{A}$, Primary sympathetic neurons were transfected with a control siRNA ( $50 \mathrm{~nm}$ ) along with a fluorescently tagged nontargeting RNA (siGLO Red, $5 \mathrm{~nm}$ ) using i-Fect (bottom) or with vehicle alone (top). Three days after application of the siRNA, the cells were visualized using a fluorescence microscope. The overlay of the phase and fluorescence images (rightmost panels) indicates that $>90 \%$ of the neurons were transfected with the siRNA, which remains in the cytoplasm. $\boldsymbol{B}$, Neurons were transfected with increasing concentrations of $\mathrm{Cbl}-3$, CD2AP, or both CD2AP and Cbl-3 siRNAs (indicated above the blots). After $72 \mathrm{~h}$, the cells were lysed and these extracts were subjected to Cbl-3 (left) or CD2AP immunoblotting (right). These immunoblots were reprobed with actin antibodies to confirm that there were similar amounts of protein in each condition (bottom). The maximal knockdown of Cbl-3 and CD2AP occurred by using $50 \mathrm{~nm}$ siRNA in sympathetic neurons. C, Sympathetic neurons were transfected with control, Cbl-3, CD2AP, or both CD2AP and $\mathrm{Cbl}-3$ siRNAs. Three days later, the neurons were then treated with medium alone or GDNF ( $50 \mathrm{ng} / \mathrm{ml})$ for $8 \mathrm{~h}$ and then detergent extracted. These extracts were subjected to immunoblot analysis for the levels of Ret51 after its immunoprecipitation, similar to Figure 7. Right, Two independent experiments were quantified and graphed as the mean \pm range. D, The extent of neuronal survival was determined in sympathetic neurons transfected with the siRNAs indicated (below each graph). Neuronal survival was assessed using two independent methods. First, the number of surviving, phase-bright neurons remaining after $2 \mathrm{~d}$ of GDNF application was counted, and a percentage of surviving neurons was calculated by counting the number of neurons in images taken before and after the GDNF treatments (left graph). Second, the number of neurons with pyknotic nuclei were counted and graphed as a percentage of apoptotic cells (right graph). These two sets of experiments were done in triplicate and graphed as the mean \pm SEM. Asterisks indicate significant differences between the control siRNA and the condition indicated, as in Figure 8. Super., Supernatant; W, Western blot.

to regulate the responsiveness of sympathetic neurons to GFLs, survival assays were conducted on SCG neurons subjected to gene silencing. Silencing of CD2AP increased significantly the survival of sympathetic neurons promoted by GDNF (Fig. 9D) (71.3\%). Knockdown of Cbl-3, in contrast, did not significantly alter GDNF-dependent survival, compared with the transfection of a noncoding control siRNA (Fig. 9D) (63.3\% survival com- pared with $56.2 \%$ survival, respectively). The partial silencing of both CD2AP and Cbl-3 led to a greater enhancement of GDNF-dependent survival, compared with the effects of CD2AP and Cbl-3 silencing alone (Fig. 9D) (89.7\% survival). A second method of ascertaining the survival effects of GDNF after siRNA transfection of sympathetic neurons was undertaken: the number of neurons undergoing apoptosis was assessed by examining their nuclear morphology. Sympathetic neurons undergoing apoptosis display pyknotic nuclei that can be readily observed using fluorescent DNA-binding dyes (Hoechst). Silencing either Cbl-3 or CD2AP enhanced significantly GDNF-dependent inhibition of apoptosis (Fig. 9D) (16.7 and $14.1 \%$ apoptosis, respectively, compared with $21.6 \%$ apoptosis in the control). The knockdown of CD2AP and Cbl-3 simultaneously led to a further inhibition of apoptosis induced by GDNF application (Fig. 9D) $(10.8 \%)$, suggesting that Cbl-3 and CD2AP function in the same pathway to regulate Ret degradation and GFL potency. Together, these data indicate that $\mathrm{CD} 2 \mathrm{AP}$ and Cbl-3 together acted as a regulatory checkpoint that limits the potency of GDNF on survival by enhancing the downregulation mechanisms for activated Ret in sympathetic neurons.

\section{Discussion}

We report here the identification of two novel Ret adaptor molecules, CD2AP and Cbl-3. In neurons, CD2AP and Cbl-3 share an unusual characteristic: they are associated preferentially with Ret in its basal, inactive state. After Ret activation, both CD2AP and Cbl-3 dissociated from Ret as a complex in which they were associated directly with each other (Fig. 10). In vitro binding experiments, using isolated proteins, revealed that neither CD2AP nor Cbl-3 show a preferential association with inactive Ret, compared with autophosphorylated Ret. This suggests that the dissociation of CD2AP and Cbl-3 from activated Ret seen in intact neurons and podocytes involves other signaling proteins, or is caused by the interaction between Cbl-3 and CD2AP, perhaps by altering their binding affinities for Ret. Cbl-3, when overexpressed in cells, inhibits Ret degradation and enhances GDNFinduced survival in neurons. In contrast, Cbl-3 coexpression with CD2AP induces the rapid degradation of activated Ret and blocks the survival effects of GDNF. When the endogenous expression of Cbl-3 and CD2AP are silenced, Ret degradation is inhibited and GDNF more effectively sustains the survival of sympathetic neurons.

CD2AP is homologous to CIN85, and like CIN85, CD2AP 
associates with c-Cbl (Kirsch et al., 2001; Cormont et al., 2003). Because CD2AP also interacts with molecules such as Rab4, CD2AP functions as a link between the ubiquitination machinery and the internalization machinery (Kirsch et al., 2001; Cormont et al., 2003; Lynch et al., 2003). CD2AP acts in the early step of internalization and endosomal sorting that ultimately results in the delivery of activated RTKs to the lysosomal degradative pathway (Cormont et al., 2003). In terms of Ret signal transduction, CD2AP associates with Ret directly, rather than indirectly via its binding to Cbl E3-ligases. However, once Ret is activated, CD2AP directly associates with Cbl-3 and augments Ret51 degradation, similar to the function of CD2AP in the degradation of other RTKs. Interestingly, expression of CD2AP 1-328, the truncated form of CD2AP that lacks the Rab4 binding site (Cormont et al., 2003), inhibits Ret turnover, suggesting that Rab4-dependent endocytic trafficking is critical for the degradation of Ret.

Cbl-3 is the least conserved member of the Cbl family of E3ligases, and Cbl-3 lacks the entire C-terminal half present in c-Cbl and Cbl-b (Keane et al., 1999; Kim et al., 1999). Although Cbl-3 does not contain the ubiquitin binding-domain (UBA) that is located in this C-terminal region, Cbl-3 has a functional ring finger domain and can downregulate RTKs such as EGFR (Keane et al., 1999; Kim et al., 2004). The function of Cbl-3 in Ret downregulation, however, is more complex. Cbl-3 overexpression alone inhibits Ret degradation, indicating that Cbl-3 can act as an antagonist of E3-ligase function, the first such example for $\mathrm{Cbl}$ family members. In contrast, when $\mathrm{CD} 2 \mathrm{AP}$ was coexpressed with Cbl-3, Cbl-3 promoted Ret degradation, presumably via its E3ligase activity. The association of Cbl-3 with Ret required a functional ring finger domain (Fig. 6), whereas the region of Cbl-3 that associates with CD2AP is not known. CD2AP associates with c-Cbl via the second $\mathrm{SH} 3$ domain of $\mathrm{CD} 2 \mathrm{AP}$, which binds to the C terminus of c-Cbl that is absent in Cbl-3 (Kirsch et al., 2001). The identification of the portions of Cbl-3 and CD2AP that are necessary for the formation of this signaling complex will provide further mechanistic insight into how Cbl proteins can trigger receptor degradation.

The results described here demonstrate that $\mathrm{Cbl}-3$ and CD2AP are physiologic Ret adaptors that act as a regulatory checkpoint governing the extent of Ret degradation after ligand activation. It is known that the kinetics of RTK downregulation directly affects the length of time that downstream signaling pathways are activated and, therefore, the cellular response to the growth factor. In PC12 cells, for example, the length of time that the ERK pathway is activated dictates whether these cells proliferate or differentiate into neurons (Qiu and Green, 1992; York et al., 2000). Thus, different cell types may respond to the same neurotrophic factor in different ways depending on their level of Cbl-3/CD2AP activity, which may explain the remarkably pleiotropic effects of GDNF in vivo (Enomoto, 2005). The Cbl-3/ CD2AP complex may also be a checkpoint critical for the modulation of GFL signaling by extracellular stimuli. NGF, for example, augments Ret signaling in sympathetic neurons, thereby enhancing their metabolism and growth (Tsui-Pierchala et al., 2002a). Remarkably, Ret signaling accounts for $30 \%$ of the growth effects of NGF on sympathetic neurons (Tsui-Pierchala et al., 2002a). NGF modulates Ret activity by inhibiting Ret degradation (Pierchala et al., 2007), and it is likely that NGF acts at this Cbl-3/CD2AP checkpoint. This hypothesis is supported by the observations that NGF inhibits the association of CD2AP with Cbl-3 and that NGF also inhibits the dissociation of Cbl-3 from activated Ret (Fig. 10). Inhibition of RTK degradation after ligand activation is a mechanism by which neurons can enhance their sensitivity to neurotrophic factors. Importantly, if other stimuli, such as neurotransmitters or calcium influx, can inhibit RTK downregulation via the Cbl-3/CD2AP checkpoint, this mechanism may contribute to synaptic plasticity and activitydependent developmental events common throughout the nervous system.

\section{References}

Arenas E, Trupp M, Akerud P, Ibáñez CF (1995) GDNF prevents degeneration and promotes the phenotype of brain noradrenergic neurons in vivo. Neuron 15:1465-1473.

Baloh RH, Tansey MG, Golden JP, Creedon DJ, Heuckeroth RO, Keck CL, Zimonjic DB, Popescu NC, Johnson EM Jr, Milbrandt J (1997) TrnR2, a novel receptor that mediates neurturin and GDNF signaling through Ret. Neuron 18:793-802.

Baloh RH, Gorodinsky A, Golden JP, Tansey MG, Keck CL, Popescu NC, Johnson EM Jr, Milbrandt J (1998a) GFRalpha3 is an orphan member of the GDNF/neurturin/persephin receptor family. Proc Natl Acad Sci U S A 95:5801-5806.

Baloh RH, Tansey MG, Lampe PA, Fahrner TJ, Enomoto H, Simburger KS, Leitner ML, Araki T, Johnson EM Jr, Milbrandt J (1998b) Artemin, a novel member of the GDNF ligand family, supports peripheral and central neurons and signals through the GFRalpha3-RET receptor complex. Neuron 21:1291-1302.

Buj-Bello A, Buchman VL, Horton A, Rosenthal A, Davies AM (1995) GDNF is an age-specific survival factor for sensory and autonomic neurons. Neuron 15:821-828.

Buj-Bello A, Adu J, Piñón LG, Horton A, Thompson J, Rosenthal A, Chinchetru M, Buchman VL, Davies AM (1997) Neurturin responsiveness requires a GPI-linked receptor and the Ret receptor tyrosine kinase. Nature 387:721-724.

Cacalano G, Fariñas I, Wang LC, Hagler K, Forgie A, Moore M, Armanini M, 
Phillips H, Ryan AM, Reichardt LF, Hynes M, Davies A, Rosenthal A (1998) GFRalpha1 is an essential receptor component for GDNF in the developing nervous system and kidney. Neuron 21:53-62.

Cormont M, Metón I, Mari M, Monzo P, Keslair F, Gaskin C, McGraw TE, Le Marchand-Brustel Y (2003) CD2AP/CMS regulates endosome morphology and traffic to the degradative pathway through its interaction with Rab4 and c-Cbl. Traffic 4:97-112.

Dikic I, Giordano S (2003) Negative receptor signalling. Curr Opin Cell Biol 15:128-135.

Durbec P, Marcos-Gutierrez CV, Kilkenny C, Grigoriou M, Wartiowaara K, Suvanto P, Smith D, Ponder B, Costantini F, Saarma M, Sariola H, Pachnis V (1996) GDNF signalling through the Ret receptor tyrosine kinase [see comments]. Nature 381:789-793.

Enokido Y, de Sauvage F, Hongo JA, Ninkina N, Rosenthal A, Buchman VL, Davies AM (1998) GFR alpha-4 and the tyrosine kinase Ret form a functional receptor complex for persephin. Curr Biol 8:1019-1022.

Enomoto H (2005) Regulation of neural development by glial cell linederived neurotrophic factor family ligands. Anat Sci Int 80:42-52.

Enomoto H, Heuckeroth RO, Golden JP, Johnson EM Jr, Milbrandt J (2000) Development of cranial parasympathetic ganglia requires sequential actions of GDNF and neurturin. Development 127:4877-4889.

Golden JP, Milbrandt J, Johnson EM Jr (2003) Neurturin and persephin promote the survival of embryonic basal forebrain cholinergic neurons in vitro. Exp Neurol 184:447-455.

Henderson CE, Phillips HS, Pollock RA, Davies AM, Lemeulle C, Armanini M, Simmons L, Moffet B, Vandlen RA, Koliatsos VE, Rosenthal A (1994) GDNF: a potent survival factor for motoneurons present in peripheral nerve and muscle [see comments] [Erratum (1995) 267:777]. Science 266:1062-1064.

Hicke L (2001) Protein regulation by monoubiquitin. Nat Rev Mol Cell Biol 2:195-201.

Keane MM, Ettenberg SA, Nau MM, Banerjee P, Cuello M, Penninger J, Lipkowitz S (1999) cbl-3: a new mammalian cbl family protein. Oncogene 18:3365-3375.

Kim JM, Wu H, Green G, Winkler CA, Kopp JB, Miner JH, Unanue ER, Shaw AS (2003) CD2-associated protein haploinsufficiency is linked to glomerular disease susceptibility. Science 300:1298-1300.

Kim M, Tezuka T, Suziki Y, Sugano S, Hirai M, Yamamoto T (1999) Molecular cloning and characterization of a novel cbl-family gene, cbl-c. Gene 239:145-154.

Kim M, Tezuka T, Tanaka K, Yamamoto T (2004) Cbl-c suppresses v-Srcinduced transformation through ubiquitin-dependent protein degradation. Oncogene 23:1645-1655.

Kirsch KH, Georgescu MM, Shishido T, Langdon WY, Birge RB, Hanafusa H (2001) The adapter type protein CMS/CD2AP binds to the protooncogenic protein c-Cbl through a tyrosine phosphorylation-regulated Src Homology 3 domain interaction. J Biol Chem 276:4957-4963.

Klein RD, Sherman D, Ho WH, Stone D, Bennett GL, Moffat B, Vandlen R, Simmons L, Gu Q, Hongo JA, Devaux B, Poulsen K, Armanini M, Nozaki C, Asai N, Goddard A, Phillips H, Henderson CE, Takahashi M, Rosenthal A (1997) A GPI-linked protein that interacts with Ret to form a candidate neurturin receptor [Erratum (1998) 392:210]. Nature 387:717-721.

Kobayashi S, Sawano A, Nojima Y, Shibuya M, Maru Y (2004) The c-Cbl/ CD2AP complex regulates VEGF-induced endocytosis and degradation of Flt-1 (VEGFR-1). FASEB J 18:929-931.

Kotzbauer PT, Lampe PA, Heuckeroth RO, Golden JP, Creedon DJ, Johnson EM Jr, Milbrandt J (1996) Neurturin, a relative of glial-cell-line-derived neurotrophic factor. Nature 384:467-470.

Lee FS, Chao MV (2001) Activation of Trk neurotrophin receptors in the absence of neurotrophins. Proc Natl Acad Sci U S A 98:3555-3560.

Lee FS, Rajagopal R, Kim AH, Chang PC, Chao MV (2002) Activation of Trk neurotrophin receptor signaling by pituitary adenylate cyclase-activating polypeptides. J Biol Chem 277:9096-9102.

Lehtonen S, Tienari J, Londesborough A, Pirvola U, Ora A, Reima I, Lehtonen E (2008) CD2-associated protein is widely expressed and differentially regulated during embryonic development. Differentiation 76:506-517.

Li L, Wu W, Lin LF, Lei M, Oppenheim RW, Houenou LJ (1995) Rescue of adult mouse motoneurons from injury-induced cell death by glial cell line-derived neurotrophic factor. Proc Natl Acad Sci U S A 92:9771-9775.

Lin LF, Doherty DH, Lile JD, Bektesh S, Collins F (1993) GDNF: a glial cell line-derived neurotrophic factor for midbrain dopaminergic neurons. Science 260:1130-1132.

Lindahl M, Timmusk T, Rossi J, Saarma M, Airaksinen MS (2000) Expression and alternative splicing of mouse Gfra4 suggest roles in endocrine cell development. Mol Cell Neurosci 15:522-533.

Lynch DK, Winata SC, Lyons RJ, Hughes WE, Lehrbach GM, Wasinger V, Corthals G, Cordwell S, Daly RJ (2003) A cortactin-CD2-associated protein $(\mathrm{CD} 2 \mathrm{AP})$ complex provides a novel link between epidermal growth factor receptor endocytosis and the actin cytoskeleton. J Biol Chem 278:21805-21813.

Milbrandt J, de Sauvage FJ, Fahrner TJ, Baloh RH, Leitner ML, Tansey MG, Lampe PA, Heuckeroth RO, Kotzbauer PT, Simburger KS, Golden JP, Davies JA, Vejsada R, Kato AC, Hynes M, Sherman D, Nishimura M, Wang LC, Vandlen R, Moffat B, et al. (1998) Persephin, a novel neurotrophic factor related to GDNF and neurturin. Neuron 20:245-253.

Moore MW, Klein RD, Fariñas I, Sauer H, Armanini M, Phillips H, Reichardt LF, Ryan AM, Carver-Moore K, Rosenthal A (1996) Renal and neuronal abnormalities in mice lacking GDNF. Nature 382:76-79.

Mount HTJ, Dean DO, Alberch J, Dreyfus CF, Black IB (1995) Glial cell line-derived neurotrophic factor promotes the survival and morphologic differentiation of Purkinje cells. Proc Natl Acad Sci U S A 92:9092-9096.

Oppenheim RW, Houenou LJ, Johnson JE, Lin LF, Li L, Lo AC, Newsome AL, Prevette DM, Wang S (1995) Developing motor neurons rescued from programmed and axotomy-induced cell death by GDNF [see comments]. Nature 373:344-346.

Petrelli A, Gilestro GF, Lanzardo S, Comoglio PM, Migone N, Giordano S (2002) The endophilin-CIN85-Cbl complex mediates ligand-dependent down regulation of c-Met. Nature 416:187-190.

Pichel JG, Shen L, Sheng HZ, Granholm AC, Drago J, Grinberg A, Lee EJ, Huang SP, Saarma M, Hoffer BJ, Sariola H, Westphal H (1996) Defects in enteric innervation and kidney development in mice lacking GDNF. Nature 382:73-76.

Pierchala BA, Milbrandt J, Johnson EM Jr (2006) Glial cell line-derived neurotrophic factor-dependent recruitment of Ret into lipid rafts enhances signaling by partitioning Ret from proteasome-dependent degradation. J Neurosci 26:2777-2787.

Pierchala BA, Tsui CC, Milbrandt J, Johnson EM Jr (2007) NGF augments the autophosphorylation of Ret via inhibition of ubiquitin-dependent degradation. J Neurochem 100:1169-1176.

Popsueva A, Poteryaev D, Arighi E, Meng X, Angers-Loustau A, Kaplan D, Saarma M, Sariola H (2003) GDNF promotes tubulogenesis of GFRalpha1-expressing MDCK cells by Src-mediated phosphorylation of Met receptor tyrosine kinase. J Cell Biol 161:119-129.

Qiu M-S, Green SH (1992) PC12 cell neuronal differentiation is associated with prolonged $\mathrm{p} 21^{\text {ras }}$ activity and consequent prolonged ERK activity. Neuron 9:705-717.

Rosenblad C, Grønborg M, Hansen C, Blom N, Meyer M, Johansen J, Dagø L, Kirik D, Patel UA, Lundberg C, Trono D, Björklund A, Johansen TE (2000) In vivo protection of nigral dopamine neurons by lentiviral gene transfer of the novel GDNF-family member neublastin/artemin. Mol Cell Neurosci 15:199-214.

Sánchez MP, Silos-Santiago I, Frisén J, He B, Lira SA, Barbacid M (1996) Renal agenesis and the absence of enteric neurons in mice lacking GDNF. Nature 382:70-73.

Schwarz K, Simons M, Reiser J, Saleem MA, Faul C, Kriz W, Shaw AS, Holzman LB, Mundel P (2001) Podocin, a raft-associated component of the glomerular slit diaphragm, interacts with CD2AP and nephrin. J Clin Invest 108:1621-1629.

Scott RP, Eketjäll S, Aineskog H, Ibáñez CF (2005) Distinct turnover of alternatively spliced isoforms of the RET kinase receptor mediated by differential recruitment of the $\mathrm{Cbl}$ ubiquitin ligase. J Biol Chem 280:13442-13449.

Shankland SJ, Ly H, Thai K, Scholey JW (1996) Glomerular expression of tissue inhibitor of metalloproteinase (TIMP-1) in normal and diabetic rats. J Am Soc Nephrol 7:97-104.

Shih NY, Li J, Karpitskii V, Nguyen A, Dustin ML, Kanagawa O, Miner JH, Shaw AS (1999) Congenital nephrotic syndrome in mice lacking CD2associated protein. Science 286:312-315.

Shih NY, Li J, Cotran R, Mundel P, Miner JH, Shaw AS (2001) CD2AP localizes to the slit diaphragm and binds to nephrin via a novel C-terminal domain. Am J Pathol 159:2303-2308.

Soubeyran P, Kowanetz K, Szymkiewicz I, Langdon WY, Dikic I (2002) Cbl- 
CIN85-endophilin complex mediates ligand-induced downregulation of EGF receptors. Nature 416:183-187.

Swaminathan G, Tsygankov AY (2006) The Cbl family proteins: ring leaders in regulation of cell signaling. J Cell Physiol 209:21-43.

Treanor JJ, Goodman L, de Sauvage F, Stone DM, Poulsen KT, Beck CD, Gray C, Armanini MP, Pollock RA, Hefti F, Phillips HS, Goddard A, Moore MW, Buj-Bello A, Davies AM, Asai N, Takahashi M, Vandlen R, Henderson CE, Rosenthal A (1996) Characterization of a multicomponent receptor for GDNF. Nature 382:80-83.

Trupp M, Rydén M, Jörnvall H, Funakoshi H, Timmusk T, Arenas E, Ibáñez CF (1995) Peripheral expression and biological activities of GDNF, a new neurotrophic factor for avian and mammalian peripheral neurons. J Cell Biol 130:137-148.

Tsui-Pierchala BA, Putcha GV, Johnson EM Jr (2000) Phosphatidylinositol 3-kinase is required for the trophic, but not the survival-promoting, actions of NGF on sympathetic neurons. J Neurosci 20:7228-7237.

Tsui-Pierchala BA, Milbrandt J, Johnson EM Jr (2002a) NGF utilizes c-Ret via a novel GFL-independent, inter-RTK signaling mechanism to maintain the trophic status of mature sympathetic neurons. Neuron 33:261-273.

Tsui-Pierchala BA, Ahrens RC, Crowder RJ, Milbrandt J, Johnson EM Jr (2002b) The long and short isoforms of Ret function as independent signaling complexes. J Biol Chem 277:34618-34625.

Tsui CC, Shankland SJ, Pierchala BA (2006) Glial cell line-derived neurotrophic factor and its receptor ret is a novel ligand-receptor complex critical for survival response during podocyte injury. J Am Soc Nephrol 17:1543-1552.

Welsch T, Endlich N, Gökce G, Doroshenko E, Simpson JC, Kriz W, Shaw AS, Endlich K (2005) Association of CD2AP with dynamic actin on vesicles in podocytes. Am J Physiol Renal Physiol 289:F1134-F1143.

York RD, Molliver DC, Grewal SS, Stenberg PE, McCleskey EW, Stork PJS (2000) Role of phosphoinositide 3-kinase and endocytosis in nerve growth factor-induced extracellular signal-regulated kinase activation via Ras and Rap1. Mol Cell Biol 20:8069-8083. 